\title{
Green measures for Mediterranean harbours under a changing climate
}

Author 1

- Joan Pau Sierra, PhD, Full Professor

- Maritime Engineering Laboratory (LIM/UPC), Department of Civil and Environmental Engineering, Polytechnic University of Catalonia, Barcelona, Spain

Author 2

- Manuel García-León, MsC in Civil Engineering

- Maritime Engineering Laboratory (LIM/UPC), Department of Civil and Environmental Engineering, Polytechnic University of Catalonia, Barcelona, Spain

Author 3

- Vicente Gracia, PhD, Associate Professor

- Maritime Engineering Laboratory (LIM/UPC), Department of Civil and Environmental Engineering, Polytechnic University of Catalonia, Barcelona, Spain

Author 4

- Agustín Sánchez-Arcilla, PhD, Full Professor

- Maritime Engineering Laboratory (LIM/UPC), Department of Civil and Environmental Engineering, Polytechnic University of Catalonia, Barcelona, Spain

Submitted: $1^{\text {st }}$ August 2016

\section{Corresponding author:}

Manuel García-León

e-mail: manuel.garcia-leon@upc.edu

Maritime Engineering Laboratory (LIM/UPC)

Department of Civil and Environmental Engineering

Polytechnic University of Catalonia

Campus Nord - D1 Building

Office D1-002

C. Jordi Girona, 1-3

08034 Barcelona (Spain)

Telephone: +34 934017017

Fax: +34 934011861 


\begin{abstract}
Harbour operability may be hampered by climate change. Green solutions can be used to provide extra flexibility with respect to present grey infrastructures to adapt and mitigate such functional disruptions with affordable costs. This paper assesses the performance of a green solution (a seagrass meadow) by assessing its effectiveness through numerical modelling. The analysis is carried out at two harbours that under present climate are prone to wave agitation and overtopping problems. The efficiency of different seagrass layouts are tested at both sites, by comparing relevant hydrodynamic parameters. It is concluded that, for moderated sea level rise (SLR) rates, illustrated by the central trend of a medium scenario from IPCC (2013), the use of seagrass meadows would be effective enough to attenuate the impact of SLR on breakwater overtopping. In addition, the use of such measures could dampen increases in port agitation due to changes in wave direction originated by climate change. Nevertheless, the complexity of interactions between hydrodynamics and seagrass would require periodic monitoring and reevaluation for maintaining acceptable risk levels, especially in case of high-end scenarios.
\end{abstract}

\title{
Keywords chosen from ICE Publishing list
}

Coastal engineering; mathematical modelling; ports, docks and harbours chosen from lists on this webpage here (if these .xlsx files open showing internet code, try using a browser that is not Internet Explorer).

\section{Introduction}

Coasts are dynamic areas that foster growth by integrating several uses (e.g. tourism, fishing, aquaculture, maritime transport, etc.) that impose a severe anthropogenic footprint. Harbour structures and operations need to combine economic and environmental objectives in a sustainable manner. Under future climates, the effects of sea level rise (SLR), changes in wave patterns and storminess may alter this fragile balance and hamper sustainable long-term coastal and port management.

Climate change has become a major focus of attention, in particular for vulnerable systems like low-lying coasts (Sánchez-Arcilla et al., 2011). In the last years, a number of studies have addressed the effects of SLR on beaches (e.g. Luo et al., 2015; Monioudi et al., 2016; Revell et al., 2011; Sánchez-Arcilla et al., 2011), coastal defense structures (e.g. Burcharth et al., 2014; Isobe, 2013), coastal ecosystems (e.g. Kane et al., 2015), overtopping of port breakwaters (Sierra et al., 2016) or flooding of urban areas (e.g. Hallegatte et al., 2011; Paudel et al., 2015). Other studies have analysed the impacts of climate change shifts of wave patterns on beaches 
(e.g. Adams et al., 2011; Casas-Prat et al., 2016; Sierra and Casas-Prat, 2014; Zacharioudaki and Reeve, 2011) or harbours (Casas-Prat and Sierra, 2010, 2012; Sierra et al., 2015). Recently, Sánchez-Arcilla et al. (2016a) assessed the impacts of SLR and changes in wave patterns on ports.

To lessen the impacts of climate change on coastal areas and activities, many studies have proposed adaptation measures (e.g. Anthoff et al., 2010; Hinkel et al., 2013, 2014; Klein et al., 2001; Linham and Nicholls, 2012; Moritz et al., 2015; Mycoo and Chadwick, 2012; SánchezArcilla et al., 2016b). The main adaptation alternatives can be categorized as grey and green measures. Grey measures correspond to conventional civil engineering works such as structure reinforcement or increasing breakwater freeboard. Green measures are solutions inspired and supported by nature, bringing natural processes to build resilience (e.g. the use of vegetation for coastal protection). The more common measures in port engineering are grey interventions that may provide immediate solutions but with high costs and rigidity (i.e. difficulty for changing the adopted measure if it does not work properly) as a drawback. In case that functionality needs are not met, the upgrading and substitution of these grey measures may be hampered due to technological limits and costs.

Grey infrastructure may induce a steady hydrodynamic behaviour that can lead to local problems (Airoldi et al. 2005). Green solutions can soften some of these drawbacks, attenuating hydrodynamic drivers through the interaction of ecological and hydraulic processes (e.g. Jones et al., 2012; Keijsers et al., 2015; Pontee et al., 2016; van Loon-Steensma, 2015). For example, vegetated areas such as salt marshes or wetlands, reduce incoming wave length and velocity, and dissipate wave energy (e.g. Horstman et al., 2014; Möller, 2006; Möller et al., 1999; Vuik et al., 2016). This green solution also decreases surge heights (Möller et al., 2014) and acts as a natural beach defence (e.g. Arkema et al., 2013; Borsje et al., 2011; Gedan et al., 2011; Temmerman et al., 2012, 2013). Various laboratory (e.g. Blackmar et al., 2013; Koftis et al., 2013; Manca et al., 2012) and field studies (e.g. Bradley and Houser, 2009; Verduin and Backhaus, 2000) have quantified the magnitude of wave attenuation facilitating the application of such green solutions for maintaining coastal resilience with affordable economic and energy costs.

Seaports, located on open coasts or estuaries, are affected by SLR, storm surges and wave storms. The increase in mean sea level or changes in wave climate will condition essential aspects of harbour operations and infrastructure, modifying risk levels and economic productivity (Sánchez-Arcilla et al., 2016a). Moreover, local problems under present climate, such as erosion induced by ship propellers (Mujal-Colilles et al. 2017), may be modulated by changes in marine drivers, adding an extra layer of complexity for harbour logistics. 
SLR will modify wave propagation patterns around and inside the harbour affecting wave agitation (oscillations within the port), siltation or structure stability (Sierra and Casas-Prat, 2014). SLR also reduces the port breakwater freeboard, increasing the magnitude and frequency of overtopping discharges and affecting the assets located at the breakwater lee side.

Changes in wave height will modify the amount of energy penetrating into harbours, while changes in wave period or direction will affect propagation processes such as shoaling, refraction and diffraction. This could induce changes in sediment transport patterns (potentially generating siltation) or wave penetration into harbours (Sierra and Casas-Prat, 2014), affecting port operability.

Most climate measures applied to harbours have been based on conventional grey engineering solutions. For this reason, this paper aims to make a preliminary assessment of the engineering performance (measured in terms of overtopping discharge and wave agitation) that green solutions can provide for port adaptation against future climates. The effectiveness of these interventions is assessed for two harbours located on the Spanish Mediterranean coast, using hydrodynamic numerical models validated for the area and vegetation parameterisations from a large-scale wave flume data. The two small-craft harbours analysed have currently exploitation problems, one due to wave agitation (Cases d'Alcanar), and the other one due to breakwater overtopping (Cala Canyelles). Simulations comprise different vegetation layouts to analyse the relationship between vegetation features and hydrodynamic wave patterns.

\section{Site description}

The two studied ports are located on the Catalan coast (NW Mediterranean), as shown in Figure 1. This is a microtidal environment with an average tidal range of about $25 \mathrm{~cm}$. The meteorology and oceanography of this area are very complex due to orographic barriers like the Pyrenees, veering winds, shadow effects caused by the Balearic Islands and irregular bathymetry (continental shelf of variable width and existence of submarine canyons close to the coast). This leads to a large spatial and seasonal variability of wind and wave fields (Lionello et al., 2002, Campins et al., 2011), with mild wave conditions most of the time (average significant wave height lower than $1 \mathrm{~m}$ ) and sporadic wave storms that can reach up to $7.5 \mathrm{~m}$ in extreme events (Sánchez-Arcilla et al., 2008). The most frequent waves are those from the East (largest heights) and South (Sánchez-Arcilla et al., 2008).

The general trend in the Mediterranean shows a relative decrease in wave energy projections (Lionello et al., 2008), though combined with SLR this can result in either higher or lower waves depending on the coastal sector due to the effects of shoaling, refraction and diffraction. These projections are similar to those of Casas-Prat and Sierra (2013) who found a general decrease of the median $\mathrm{H}_{\mathrm{s}}$ in most of the NW Mediterranean, with local rises of this parameter (e.g. Gulf 
of Genoa). The seasonal wave distribution will also change, with greater median $\mathrm{H}_{\mathrm{s}}$ in summer and lower in winter. Extreme events will decrease in frequency, but they may increase in intensity. Results also show changes in the seasonal distribution of directional frequencies which, in turn, can generate changes in sediment transport patterns or in the amount of wave energy penetrating into ports, whose entrances are usually oriented towards the South.

\section{Methodology}

To assess the performance of green interventions under future climates some plausible scenarios must be selected, derived from the last projections presented by the IPCC (2013) in its $5^{\text {th }}$ Assessment Report (AR5).

The IPCC-AR5 maps of SLR for the Mediterranean Sea (IPCC, 2013) indicate the possibility of an increase slightly lower (about 10\%) than the global mean. Hence, the following estimations by the end of the century can be proposed, taking into account the IPCC (2013) scenarios and this $10 \%$ reduction: $0.47 \mathrm{~m}$ for RCP 4.5 (central estimate) and $0.88 \mathrm{~m}$ for RCP 8.5 (upper band) scenarios. A high-end SLR scenario (HES) of $1.8 \mathrm{~m}$ has also been considered. This is consistent with studies (e.g. Mori et al., 2013) that suggest reaching global SLR near $1.86 \mathrm{~m}$ or even $2 \mathrm{~m}$ (Rahmstorf, 2007) by 2100. These studies indicate that a sharp increase of mean sea level is possible, despite that the probability of occurrence is low (less than $5 \%$ ), but non negligible (Jevrejeva et al., 2014). Figure 2 shows the evolution of SLR during the $21^{\text {st }}$ century for the three scenarios considered.

To compute overtopping discharges over the selected port breakwaters, the Empirical Methods proposed by the European Overtopping Manual (Pullen et al., 2007) are used, based on the values of wave height and structure freeboard, so that a proper wave propagation until the breakwater toe is essential. The SWAN model (Booij et al., 1999) is chosen for this propagation, because of its ability to reproduce energy dissipation due to vegetation (Vuik et al., 2016). This code has a vegetation module that has been validated by Suzuki et al. (2012). To assess the effects of vegetation, selected waves are propagated with and without vegetation in front of Cala Canyelles port breakwater, computing $\mathrm{H}_{\mathrm{s}}$ at the breakwater toe in both cases. The computed $\mathrm{H}_{\mathrm{s}}$ values are then used to estimate overtopping discharges. Waves corresponding to three return periods are considered: 1 year (frequent storms), 5 years (intense storms) and 50 years (exceptional storms). The first and second return periods are typically used to determine the port operability whereas the last stands for the breakwater design conditions. In each case, six possible wave directions are analysed, due to the location of the port within a bay: E, ESE, SE, SSE, S and SSW. The resulting 18 wave conditions (3 return periods $x 6$ directions) have been used in 4 scenarios of SLR: $0 \mathrm{~cm}$ (to account for present conditions) and the previously mentioned future scenarios of SLR: $47 \mathrm{~cm}, 88 \mathrm{~cm}$ and $180 \mathrm{~cm}$, totaling 72 hydrodynamic conditions. All these combination of waves and SLR are taken into account to carry out wave 
propagations over three bottom configurations: no vegetation (present state) and two vegetation meadows, a sparse configuration with $50 \mathrm{stems} / \mathrm{m}^{2}$ and a dense layout with $100 \mathrm{stems} / \mathrm{m}^{2}$. The resulting combination of wave conditions, mean water levels and vegetation layouts has given a total of 216 simulations. Figure 3 shows the location and dimensions of the seagrass meadow, with a cross-shore width of $160 \mathrm{~m}$ and the same length as the breakwater (about $100 \mathrm{~m}$ ). The stem height in all cases is $1 \mathrm{~m}$. The drag coefficient has been computed using Myrhaug and Holmedal (2011). The seagrass has been placed in front of the breakwater to damp incoming waves and reduce overtopping. The cross-shore width of the meadow has been defined to span several wave lengths and, thus, guarantee an efficient wave attenuation.

To study port agitation, SWAN may not be the preferred tool, because the involved physical processes demand a phase-resolving approximation. Therefore, a Bousinessq-type (BT) model, that can handle shoaling, refraction, diffraction, reflection, bottom friction and non-linear interactions is chosen instead. A wide description of the advantages, disadvantages and performance of this type of models can be found in Filippini et al. (2015).

To account for the effect of vegetation in this type of models, there are two possible approaches:

- Through a drag coefficient, whose value depends on the meadow features (stem length, stem diameter, plant density...). In this case the Boussinesq equations are modified by adding an extra term to account for the drag forces generated by the vegetation (e.g. Huang et al., 2011).

- Through a friction factor that is calibrated with laboratory experiments, to obtain this factor as a function of the stem density and Ursell number (e.g. Blackmar et al., 2013; Lynett et al., 2002).

In this paper the second approach is followed, calibrating the friction factor of the BT model with data from the experiments of Koftis et al. (2013). To assess the effect of vegetation on wave attenuation inside the harbour, two meadow configurations of Zostera marina have been placed between the two breakwaters of the Cases d'Alcanar port. Figure 4 shows the location and dimensions of both configurations. Layout A covers an area of $5175 \mathrm{~m}^{2}(115 \times 45 \mathrm{~m})$ whereas layout $B$ represents a large solution with $7250 \mathrm{~m}^{2}(145 \times 50 \mathrm{~m})$. Zostera marina is the dominant seagrass species of the northern hemisphere, being present in the Atlantic and Pacific Oceans and the Mediterranean, Baltic and North Seas (Reusch et al., 2000). The density assumed is high $\left(360 \mathrm{stems} / \mathrm{m}^{2}\right)$ to be the same used by Koftis et al. (2013) in lab experiments. The meadows are placed at the port mouth to minimize the wave energy penetrating within the harbour. 
Since for port agitation SLR is not as critical as for breakwater overtopping, in Cases d'Alcanar case only the effect of climate change on waves has been taken into account without considering any SLR scenario. To perform the agitation analysis, the wave climate described in Casas-Prat and Sierra (2013) and the methodology followed in Sierra et al. (2015) have been chosen. Wave projections obtained with the SWAN model forced by winds generated with five combinations of global (GSMs) and regional circulations models (RCMs) that consider the A1B scenario of the $4^{\text {th }}$ Assessment Report from IPCC (2007) have been used since no AR5 downscaled projections were available. For the five wave datasets, present (1971-2000) and future (2071-2100) wave conditions have been selected. For each wave dataset, three directions (E, SE and S, due to the proximity of the Ebro Delta, (Sánchez-Arcilla et al. (2008)) and five representative wave heights $(0.5,1.5,2.5,3.5$ and $5 \mathrm{~m})$ have been taken into account to assess port agitation, meaning 75 simulations for each of the 4 studied conditions (present waves without vegetation and future waves without vegetation, with layout $A$ and with layout $B$ ).

\section{Results}

A sample computation of the improvement in breakwater overtopping achieved by vegetation is shown in Figure 5. The figure indicates the magnitude of wave height reduction around Cala Canyelles port depending on whether vegetation is present or not, for a particular case of wave and SLR conditions (waves from the South, with $\mathrm{H}_{\mathrm{s} 0}=5 \mathrm{~m}$ and $\mathrm{SLR}=0.47 \mathrm{~m}$, where $\mathrm{H}_{\mathrm{s} 0}$ is the offshore significant wave height). This example illustrates how the presence of seagrass reduces wave height in the vegetated area, this reduction increases as the wave propagates through the meadow, reaching a minimum wave height at the toe of the breakwater. In the example, a maximum attenuation of $40 \%$ is provided at the shallowest position of the meadow at about $4 \mathrm{~m}$ depth.

In Figure 6, the results of wave propagation for all the studied cases are summarized by plotting the ratio between the significant wave heights obtained at the toe of the breakwater with vegetation $\left(\mathrm{H}_{\mathrm{sv}}\right)$ and without vegetation $\left(\mathrm{H}_{\mathrm{swv}}\right)$. The left graph shows the results for $50 \mathrm{stems} / \mathrm{m}^{2}$ and the right one corresponds to $100 \mathrm{stems} / \mathrm{m}^{2}$. It is apparent that wave attenuation increases with vegetation density, as shown also in Table 1 . For a density of $100 \mathrm{stems} / \mathrm{m}^{2}$ the decrease induced by vegetation is almost twice that the obtained when the density is $50 \mathrm{stems} / \mathrm{m}^{2}$.

There is a general trend indicating larger attenuation when $\mathrm{H}_{\mathrm{s} 0}$ is greater, despite some modulation due to the wave period, which also has a certain influence in wave attenuation. Thus, for $\mathrm{H}_{\mathrm{s} 0}=2.77 \mathrm{~m}$ the average reduction considering all cases is $2.8 \%$, whereas for $\mathrm{H}_{\mathrm{s} 0}=$ $9.59 \mathrm{~m}$ the average decrease reaches $24.6 \%$.

Higher SLR leads to lower wave attenuation, as shown in Table 1 and Figure 6, although the effect of SLR is less than that of vegetation density. Thus, for $50 \mathrm{stems} / \mathrm{m}^{2}$ the average 
reduction of wave height decreases from $11.4 \%$ (for $\operatorname{SLR}=0.0 \mathrm{~m}$ ) to $8.7 \%$ (for $\operatorname{SLR}=1.80 \mathrm{~m}$ ), while for $100 \mathrm{stems} / \mathrm{m}^{2}$ the decrease is from $21.1 \%$ (for $\mathrm{SLR}=0.0 \mathrm{~m}$ ) to $16.4 \%$ (for $\mathrm{SLR}=1.80$ $\mathrm{m})$.

The reduction of wave height entails a lower overtopping discharge, as it can be observed in Figure 7 , where the ratio of this discharge with vegetation $\left(q_{v}\right)$ and without vegetation $\left(q_{w v}\right)$ is presented for all the simulated cases. The decrease of overtopping discharges follows the same trends as the wave height attenuation, but magnified due to the non-linear relationship between both parameters. Thus, for example, for $50 \mathrm{stems} / \mathrm{m}^{2}$ and the highest offshore waves, the reduction of significant wave height at the toe of the breakwater due to vegetation ranges between $15.4 \%$ and $19.3 \%$ (depending on the magnitude of SLR), while the decrease of overtopping discharge varies between $29.7 \%$ and $59 \%$. For the $100 \mathrm{stems} / \mathrm{m}^{2}$ cases, these reductions vary from $28.1 \%$ to $34.2 \%$ for wave heights and $51 \%$ to $84.5 \%$ for overtopping discharges.

In Table 2 the impact of SLR on overtopping discharges (with respect to present conditions without vegetation) is presented, showing the performance of different vegetation densities in this port. In the cases without vegetation, a SLR of $0.47 \mathrm{~m}$ almost doubles the present overtopping discharge, whilst a SLR of $0.88 \mathrm{~m}$ would more than triple the present volumes and a high-end scenario (SLR $=1.80 \mathrm{~m}$ ) would increase overtopping by an order of magnitude. The introduction of vegetation with a moderate density $\left(50 \mathrm{stems} / \mathrm{m}^{2}\right)$ would reduce significantly the previous discharge increases, although only in the case of no SLR would the present overtopping rates be reduced. The increase in vegetation density $\left(100 \mathrm{stems} / \mathrm{m}^{2}\right)$ would reduce more the resulting overtopping and it could even compensate a SLR of $0.47 \mathrm{~m}$.

Another factor that has been analysed is the reduction of overtopping discharge due to the presence of seagrass meadows as a function of wave direction. In Figure 8, the percentage reduction of this discharge is presented for two cases: present bathymetry and SLR of $0.47 \mathrm{~m}$ (corresponding to the central band of RCP4.5 scenario). The analysis has been performed for the 6 wave directions (E, ESE, SE, SSE, S and SSW) of interest for the selected port. The lowest reductions are obtained in all cases for SE and SSE sectors, followed by S component. On the contrary, E and ESE sectors present the largest overtopping reductions.

Figure 9 shows a sample computation of the port agitation due to vegetation at the Cases d'Alcanar port. The upper panel illustrates the wave field generated by the propagation of an irregular time series with $\mathrm{H}_{\mathrm{s} 0}=2.5 \mathrm{~m}$ from the East for present conditions. The simulated wave field inside the harbour ranges from $\mathrm{H}_{\mathrm{s}}=0.1 \mathrm{~m}$ to $0.3 \mathrm{~m}$. Larger wave heights are found close to the entrance, ranging from $1.2 \mathrm{~m}$ to $0.4 \mathrm{~m}$. The middle panel of Figure 9 shows the variation (in percentage) of $\mathrm{H}_{\mathrm{s}}$ when the seagrass meadow $\mathrm{A}$ of Figure 4 is placed in the port mouth. In most of the domain the variations are rather low, below 2.5\%. Major reductions are found in the immediate area of influence of the meadow with reduction rates between $5 \%$ and $15 \%$ over the 
seagrass and up to $40 \%$ close to the dike outside the seagrass. In the bottom panel of Figure 9 , the percentage of variation of $H_{s}$ with layout $B$ is presented. The results are similar to those of the middle panel, although wave reduction is enhanced, in particular within the port.

In Table 3 the port average agitation variations for the selected models and layouts studied are summarized. If the present configuration (no vegetation) is maintained, the comparison between present and future wave climates shows future increases in agitation between $3 \%$ and $4 \%$ for Cases d'Alcanar port. A significant reduction of agitation is obtained in all models when seagrass is placed in the port mouth. The effect of the layout A meadow, shown in Figure 4 left, results in a future averaged agitation reduced $6.9 \%$. If a larger meadow is considered (layout $B$, Figure 4 right) the total reduction is about $7.7 \%$.

\section{Discussion}

The use of a seagrass meadow as a "green" solution for reducing the impact of climate change on breakwater overtopping and wave agitation in ports is a promising alternative but requires further quantification and engineering criteria.

The obtained results show that placing a vegetation meadow in front of port breakwaters reduces significantly the wave height at the breakwater toe. The magnitude of this reduction depends on the density of plants. Of the two configurations analysed here, the denser one (100 stems $/ \mathrm{m}^{2}$ ) generated reductions of $\mathrm{H}_{\mathrm{s}}$ at the breakwater toe almost twice those of the less dense meadow $\left(50 \mathrm{stems} / \mathrm{m}^{2}\right.$ ). These lower wave heights lead, in turn, to lower overtopping rates. For present sea level conditions, a meadow with a density of $50 \mathrm{stems} / \mathrm{m}^{2}$ generates overtopping reductions between $13 \%$ and $59 \%$ depending on the wave height, while doubling the plant density would reduce overtopping between $24 \%$ and $84 \%$. These results are in line with Manca et al. (2012) and Koftis et al. (2013) who indicated that wave attenuation is greater for larger plant densities (number of stems per square meter).

As expected, higher wave heights experience larger reduction by the meadow. In shallow areas the seagrass meadow effect on wave kinematics is mainly controlled by wave slope and depth. As a result, the seagrass meadow induces greater wave energy dissipation for higher waves. This is due to the greater orbital velocities associated to the higher waves which, in turn, give rise to larger Reynolds numbers and turbulent dissipation. In addition, waves with larger wave lengths are more attenuated (Koftis et al. (2013))..

Another factor that significantly bounds the overtopping discharge is SLR because it reduces the freeboard and increases the water depth, allowing higher waves to reach the breakwater without breaking. This has become a key point for Cala Canyelles, representing a small freeboard harbour (about $2.5 \mathrm{~m}$ above the mean water level). Even a SLR of $0.47 \mathrm{~m}$ would 
generate overtopping flows that double those under present conditions. Vegetation would reduce these volumes, but a density of $50 \mathrm{stems} / \mathrm{m}^{2}$ would not be enough for keeping present discharges. Denser meadows $\left(100 \mathrm{stems} / \mathrm{m}^{2}\right.$ ) would compensate this SLR increase of $0.47 \mathrm{~m}$ for the directions that induce greater overtopping, albeit for the directions with lower present discharges (SE to $S$ ) the flows would be larger than now. The deployment of vegetation could, thus, offset the impact of SLR on overtopping and without any additional grey engineering measure. The average overtopping (all directions) would be reduced about $14 \%$ for the studied case $\left(\mathrm{SLR}=0.47 \mathrm{~m}\right.$ and $\left.100 \mathrm{stems} / \mathrm{m}^{2}\right)$ with respect to the present situation.

For larger values of SLR (0.88 or $1.80 \mathrm{~m}$ ), the vegetation patch would reduce overtopping discharges but would not be enough to keep present values. In this case, additional grey measures would be necessary to mantain the port infrastructure and operations.

The depth influence on wave height reduction has been investigated for the Cala Canyelles case. Several field studies (Möller et al., 1999; Bradley and Houser, 2009) have shown that most of the wave height reduction occurred with a few meters of vegetation patch. In addition, laboratory tests (Manca et al., 2012; Koftis et al., 2013) concluded that the wave height reduction is larger for high submergence ratios, which is the ratio between stem height and water depth. Figure 5 confirms these previous results because in a large part of the meadow (the one with the lowest submergence ratios) the wave attenuation is relatively small. This suggest that, probably, the size (cross-shore width) of the meadow could be reduced, obtaining similar results.

The influence of wave direction on wave attenuation and overtopping discharge has also been analysed. The lowest decreases in both variables are obtained for SE and SSE directions while the greatest reductions are associated to waves from E and ESE, showing the sensitivity to direction and domain effective geometry. Directions with larger reductions are those presenting higher wave heights and lengths. On the contrary, directions with the lowest decreases are those with the smallest wave heights and lengths. The Cala Canyelles port situation, within a bay, gives rise to diffraction and refraction processes that change the direction of waves, which arrive almost perpendicular to the port breakwater. For this type of geometry, future changes in wave directions due to climate would not significantly affect (by themselves) overtopping discharges via the directional sector.

With respect to agitation our study suggests future increases due to changes in the frequency of wave directions which may enhance wave penetration within the harbour, unless the layout is modified.

The placement of a vegetation patch in front of the port entrance would lead to a reduction of wave heights within the harbour. The plant canopy could compensate future increases of wave 
energy inside the harbour. This means that submerged plants could be used as an effective protection system under future climates, beneficial for agitation and dike functionality, enhanced by the fact that close to the dike any increase of wave height due to the combination of incident and reflected waves would also be damped.

The benefits of using a larger vegetation surface located at the same place are not conclusive, obtaining only slight additional reductions of port agitation. This means that an increase of $40 \%$ in the meadow surface only generates a marginal decrease of significant wave height. This is in agreement with Möller et al. (1999) and Manca et al. (2012) who stated that most of the height wave reduction occurred in the first few metres of a vegetation field. Therefore, the wave damping generated by vegetation meadows has a certain limit after which the benefits are minimal. An important practical implication of this is that seagrass to reduce incoming wave energy can be of limited extent, facilitating maintenance.

The effects of SLR on wave heights outside the port cannot be estimated in general terms, since shoaling and refraction depend on water depth, wave period and port geometry, so at each case the response will be different either increasing or decreasing $\mathrm{H}_{\mathrm{s}}$. However, as pointed out by Sierra et al. (2017), greater water depths will lead to larger diffraction coefficients at the breakwater, so that waves arriving to the port mouth will penetrate more, generating larger port agitation. The combination of factors may result in positive (reducing agitation) or negative (increasing $\mathrm{H}_{\mathrm{s}}$ within the port) differences, which should be studied on a case-by-case basis. The results presented here suggest that submerged vegetation could nevertheless contribute to reduce the potential negative impacts of SLR on port agitation.

An additional benefit of green solutions, compared to the classical grey alternatives, is that they contribute to $\mathrm{CO}_{2}$ sequestration and have smaller environmental and visual impact. They are also of great ecological importance, contributing to maintain biodiversity since they can serve as important nursery grounds for numerous species of algae, fish and invertebrates both above and below the seabed (Koftis et al., 2013). They are also more flexible than rigid structural solutions, allowing changes in their layout to comply with future climate uncertainty.

On the contrary, these meadows contribute to sedimentation by slowing down water motion and by reducing sediment suspension (Fonseca and Cahalan, 1992). This can lead to a reduction of the available depth for boats. In addition, seagrass may disturb navigation if the clearance above the plants is too small.

Green solutions require a periodic evaluation of their performance. The limited experience of their behaviour and evolution over time adds a new layer of uncertainty, not only in the design, but also in the maintenance phase. In-situ and remote sensing monitoring can help to determine relevant indicators such as biota stress and growth rates and associated water quality. This 
timely information can serve to redefine these interventions indicating whether further additional measures are required. Hence, "working with nature" demands long-term planning, including contingency plans in case that the expected results are not obtained.

\section{Conclusions}

This study is a first attempt to assess the benefits of vegetation patches for harbour adaptation to climate change. It has shown via numerical modelling that green solutions may diminish agitation and overtopping hazards for future and present conditions. The hydrodynamic behaviour of submerged meadows has been simulated with state-of-the-art parameterizations, evidencing that seagrass can produce significant wave attenuation, thus contributing to reduce the impacts due to climate change.

In the case of Cala Canyelles port, a meadow has been placed in the offshore side of the main breakwater for attenuating waves and thus reducing overtopping. The obtained results indicate that the presence of seagrass reduces overtopping in all studied cases, but it would only compensate overtopping increases for moderate values of SLR (RCP 4.5 scenario) with a density of $100 \mathrm{stems} / \mathrm{m}^{2}$. The influence of SLR and meadow density on overtopping discharges needs to be further investigated, as a function of breakwater freeboard and port geometry. Moreover, the definition of the optimal surface required is an issue that demands an in-depth analysis.

In the case of Cases d'Alcanar port, the obtained results show that placing seagrass meadows in front of the port mouth can significantly reduce port agitation, compensating the changes in wave direction due to climate change that could favour the penetration of waves within the port. Increasing the meadow area does not produce an improvement proportional to the surface extension. The influence of meadow layout and density in the reduction of port agitation is a topic that also needs further research. In addition, the effect of SLR on port agitation and how submerged vegetation can contribute to correct its potential negative effects is still a partially open question.

Green interventions like submerged seagrass show a number of benefits, including performance, when compared to conventional harbour engineering. They can even compensate some of the negative effects of climate change. Nevertheless, the efficacy of this type of measures is limited, because they are only effective in attenuating waves when the ratio between stem height and water depth is within a certain range. The clear delimitation of application ranges and criteria under real field conditions will be required for a wide use of these natural solutions.

\section{Acknowledgements}


This paper has received funding from the European Union's H2020 Programme for Research, Technological Development and Demonstration under Grant Agreement No H2020-EO-2016730030-CEASELESS. It has been supported by the EU-project RISES-AM (FP7-ENV-603396) and the Spanish national project PLAN-WAVE (CTM2013-45141-R). We would also like to thank the Secretary of Universities and Research of the Department of Economics of the Catalan Generalitat (Ref. 2014SGR1253). The second author acknowledges the PhD scholarship from the Government of Catalonia (DGR FI-AGAUR-14).

\section{References}

Adams, P.N., Inman, D.L. and Lovering, J.L., 2011. Effects of climate change and wave direction on longshore sediment transport patterns in Southern California. Climatic Change, 109(1): 211-228.

Airoldi, L., Abbiati, M., Beck, M.W., Hawkins, S.J., Jonsson, P.R., Martin, D., Moschella, P.S., Sundelöf, A., Thompson, R.C., Aberg, P., 2005. An ecological perspective on the deployment and design of low-crested and other hard coastal defence structures. Coastal Engineering, 52, 1073-1087.

Anthoff, D., Nicholls, R.J. and Tol, R.S.J., 2010. The economic impact of substantial sea-level rise. Mitigation and Adaptation Strategies for Global Change, 15(4): 321-335.

Arkema, K.K., Guannel, G., Verutes, G., Wood, S.A., Guerry, A., Ruckelshaus, M., Kareiva, P., Lacayo, M. and Silver, J.M., 2013. Coastal habitats shield people and property from sea-level rise and storms. Nature Climate Change, 3(10): 913-918.

Blackmar, P.J., Cox, D.T. and Wei-Cheng, W., 2013. Laboratory observations and numerical simulations of wave height attenuation in heterogeneous vegetation. Journal of Waterway, Port, Coastal, and Ocean Engineering, 140(1): 56-65.

Booij, N., Ris, R.C. and Holthuijsen, L.H., 1999. A third-generation wave model for coastal regions, Part I, Model description and validation. Journal of Geophysical Research, 104 (C4): 7649-7666.

Borsje, B.W., van Wesenbeeck, B.K., Dekker, F., Paalvast, P., Bouma, T.J., van Katwijk, M.M. and de Vries, M.B., 2011. How ecological engineering can serve in coastal protection. Ecological Engineering, 37: 113-122.

Bradley, K. and Houser, C., 2009. Relative velocity of seagrass blades: Implications for wave attenuation in low-energy environments. Journal of Geophysical Research: Earth Surface, 114 (F01004).

Burcharth, H.F., Andersen, T.L. and Lara, J.L., 2014. Upgrade of coastal defence structures against increased loadings caused by climate change: A first methodological approach. Coastal Engineering, 87: 112-121.

Campins, J., Genovés, A., Picornell, M.A. and Jansà, A., 2011. Climatology of Mediterranean cyclones using the ERA-40 dataset. International Journal of Climatology, 31: 15961614

Casas-Prat, M., Mclnnes, K.L., Hemer, M.A. and Sierra, J.P., 2016. Future wave-driven coastal sediment transport along the Catalan coast (NW Mediterranean). Regional Environmental Change, 16: 1739-1750.

Casas-Prat, M. and Sierra, J.P., 2010. Trend analysis of wave storminess: wave direction and its impact on harbour agitation. Natural Hazards and Earth System Sciences, 10: 23272340.

Casas-Prat, M. and Sierra, J.P., 2012. Trend analysis of wave direction and associated impacts on the Catalan coast. Climatic Change, 115: 667-691.

Casas-Prat, M. and Sierra, J.P., 2013. Projected Future Wave Climate in the NW Mediterranean Sea. Journal of Geophysical Research: Oceans, 118: 3548-3568.

Filippini, A.G., Bellec, S., Colin, M. and Ricchiuto, M., 2015. On the nonlinear behaviour of Boussinesq type models: Amplitude-velocity vs amplitude-flux forms. Coastal Engineering, 99: 109-123.

Fonseca, M.S. and Cahalan, J.H., 1992. A preliminary evaluation of wave attenuation by four species of seagrass. Estuarina, Coastal and Shelf Science, 35: 565-576. 
Gedan, K.B., Kirwan, M.L., Wolanski, E., Barbier, E.B. and Silliman, B.R., 2011. The present and future role of coastal wetland vegetation in protecting shorelines: answering recent challenges to the paradigm. Climatic Change, 106(1): 7-29.

Hallegatte, S., Ranger, N., Mestre, O., Dumas, P., Corfee-Morlot, J., Herweijer, C. and Wood, R.M., 2011. Assessing climate change impacts, sea level rise and storm surge risk in port cities: a case study on Copenhagen. Climatic Change, 104(1): 113-137.

Hinkel, J., Lincke, D., Vafeidis, A.T., Perrette, M., Nicholls, R.J., Tol, R.S.J., Marzeion, B., Fettweis, X., Cezar, I. and Levermann, A., 2014. Coastal flood damage and adaptation costs under 21st century sea-level rise. Proceedings of the National Academy of Sciences, 111(9): 3292-3297.

Hinkel, J., van Vuuren, D.P., Nicholls, R.J. and Klein, R.J.T., 2013. The effects of adaptation and mitigation on coastal flood impacts during the 21st century. An application of the DIVA and IMAGE models. Climatic Change, 117(4): 783-794.

Horstman, E.M., Dohmen-Janssen, C.M., Narra, P.M.F., van den Berg, N.J.F., Siemerink, M. and Hulscher, S.J.M.H., 2014. Wave attenuation in mangroves: A quantitative approach to field observations. Coastal Engineering, 94: 47-62.

Huang, Z., Yao, Y., Sim, S.Y. and Yao, Y., 2011. Interaction of solitary waves with emergent, rigid vegetation. Ocean Engineering, 38(10): 1080-1088.

IPCC, 2007. Climate Change 2007: The Physical Science Basis. Contribution of Working Group I to the Fourth Assessment Report of the Intergovernmental Panel on Climate Change. Cambridge University Press, Cambridge, United Kingdom and New York, NY, USA, 996 pp.

IPCC, 2013. Climate Change 2013: The Physical Science Basis. Contribution of Working Group I to the Fifth Assessment Report of the Intergovernmental Panel on Climate Change. Cambridge University Press, Cambridge, United Kingdom and New York, NY, USA, $1535 \mathrm{pp}$.

Isobe, M., 2013. Impact of global warming on coastal structures in shallow water. Ocean Engineering, 71: 51-57.

Jevrejeva, S., Grinsted, A. and Moore, J.C., 2014. Upper limit for sea level projections by 2100. Environmental Research Letters, 9(10): 104008.

Jones, H.P., Hole, D.G. and Zavaleta, E.S., 2012. Harnessing nature to help people adapt to climate change. Nature Climate Change, 2(7): 504-509.

Kane, H.H., Fletcher, C.H., Frazer, L.N. and Barbee, M.M., 2015. Critical elevation levels for flooding due to sea-level rise in Hawaii. Regional Environmental Change, 15(8): 16791687.

Keijsers, J.G.S., Giardino, A., Poortinga, A., Mulder, J.P.M., Riksen, M.J.P.M. and Santinelli, G., 2015. Adaptation strategies to maintain dunes as flexible coastal flood defense in The Netherlands. Mitigation and Adaptation Strategies for Global Change, 20(6): 913-928.

Klein, R.J.T., Nicholls, R.J., Ragoonaden, S., Capobianco, M., Aston, J. and Buckley, E.N., 2001. Technological Options for Adaptation to Climate Change in Coastal Zones. Journal of Coastal Research, 17(3): 531-543.

Koftis, T., Prinos, P. and Stratigaki, V., 2013. Wave damping over artificial Posidonia oceanica meadow: A large-scale experimental study. Coastal Engineering, 73: 71-83.

Linham, M.M. and Nicholls, R.J., 2012. Adaptation technologies for coastal erosion and flooding: a review. Proceedings of the Institution of Civil Engineers-Maritime Engineering, 165: 95-112.

Lionello, P., Cogo, S., Galati, M.B. and Sanna, A., 2008. The Mediterranean surface wave climate inferred from future scenario simulations. Global and Planetary Change, 63(23): 152-162.

Lionello, P., Dalan, F. and Elvini, E., 2002. Cyclones in the Mediterranean region: The present and the doubled CO2 climate scenarios. Climate Research, 22: 147-159.

Luo, J., Li, M., Sun, Z. and Wang, W., 2015. Impacts of sea level rise on morphodynamics in Liverpool Bay. Proceedings of the Institution of Civil Engineers-Maritime Engineering, 168: 3-19.

Lynett, P.J., Tso-Ren, W. and Liu, P.L.-F., 2002. Modeling wave runup with depth-integrated equations. Coastal Engineering, 46(2): 89-107.

Manca, E., Caceres, I., Alsina, J.M., Stratigaki, V., Townend, I. and Amos, C.L., 2012. Wave energy and wave-induced flow reduction by full-scale model Posidonia oceanica seagrass. Continental Shelf Research, 50-51: 100-116. 
Möller, I., 2006. Quantifying saltmarsh vegetation and its effect on wave height dissipation: Results from a UK East coast saltmarsh. Estuarine, Coastal and Shelf Science, 69(34): 337-351.

Möller, I., Kudella, M., Rupprecht, F., Spencer, T., Paul, M., van Wesenbeeck, B.K., Wolters, G., Jensen, K., Bouma, T.J., Miranda-Lange, M. et al., 2014. Wave attenuation over coastal salt marshes under storm surge conditions. Nature Geoscience, 7(10): 727-731.

Möller, I., Spencer, T., French, J.R., Leggett, D.J. and Dixon, M., 1999. Wave transformation over salt marshes: A field and numerical modelling study from North Norfolk, England. Estuarine, Coastal and Shelf Science, 49(3): 411-426.

Monioudi, I.N., Karditsa, A., Chatzipavlis, A., Alexandrakis, G., Andreadis, O.P., Velegrakis, A.F., Poulos, S.E., Ghionis, G., Petrakis, S., Sifnioti, D., Hasiotis, T., Lipakis, M., Kampanis, N., Karambas, T. and Marinos, E., 2016. Assessment of vulnerability of the eastern Cretan beaches (Greece) to sea level rise. Regional Environmental Change, 16: 1951-1962.

Mori, N., Shimura, T., Yasuda, T. and Mase, H., 2013. Multi-model climate projections of ocean surface variables under different climate scenarios-Future change of waves, sea level and wind. Ocean Engineering, 71: 122-129.

Moritz, H., White, K., Gouldby, B., Sweet, W., Ruggiero, P., Gravens, M., O'Brien, P., Moritz, H., Wahl, T., Nadal-Caraballo, N.C. et al., 2015. USACE adaptation approach for future coastal climate conditions. Proceedings of the Institution of Civil Engineers-Maritime Engineering, 168: 111-117.

Mujal-Colilles, A., Gironella, X., Sánchez-Arcilla, A., Puig, C. and García-León, M., 2017. Erosion caused by propeller jets in a low energy harbour basin. Journal of Hydraulic Research, 55: 121-128.

Mycoo, M. and Chadwick, A., 2012. Adaptation to climate change: the coastal zone of Barbados, Proceedings of the Institution of Civil Engineers-Maritime Engineering, 165: 159-168.

Myrhaug, D. and Homedal L.E., 2011. Drag force on a vegetation field due to long-crested and short-crested nonlinear random waves. Coastal Engineering, 58: 562-566.

Paudel, Y., Botzen, W.J.W. and Aerts, J.C.J.H., 2015. Influence of climate change and socioeconomic development on catastrophe insurance: a case study of flood risk scenarios in the Netherlands. Regional Environmental Change, 15(8): 1717-1729.

Pontee, N., Narayan, S., Beck, M.W. and Hosking, A.H., 2016. Nature-based solutions: lessons from around the world. Proceedings of the Institution of Civil Engineers-Maritime Engineering, 169(MA1): 29-36.

Pullen, T., Allsop, N., Bruce, T., Kortenhaus, A., Schutrumpf, H. and Van Der Meer, J., 2007. EurOtop: Wave Overtopping of Sea Defences and Related Structures: Assessment Manual. 178p., Environment Agency, UK/Expertise Netwerk Waterkeren, NL/Kuratorium fur Forschung im Kusteningenieurwesen, Germany.

Rahmstorf, S. 2007. A semi-empirical approach to projecting future sea-level rise. Science, 315: 368-370

Reusch, T.B.H., Stam, W.T. and Olsen, J.L., 2000. A microsatellite-based estimation of clonal diversity and population subdivision in Zostera marina, a marine flowering plant. Molecular Ecology, 9: 127-140.

Revell, D.L., Battalio, R., Spear, B., Ruggiero, P. and Vandever, J., 2011. A methodology for predicting future coastal hazards due to sea-level rise on the California Coast. Climatic Change, 109(1): 251-276.

Sánchez-Arcilla, A., García-León, M., Gracia, V., Devoy, R., Stanica, A. and Gault, J., 2016b. Managing coastal environments under climate change: Pathways to adaptation. Science of The Total Environment, 572: 1336-1352.

Sánchez-Arcilla, A., González-Marco, D. and Bolaños, R., 2008. A review of wave climate and prediction along the Spanish Mediterranean coast. Natural Hazards and Earth System Science, 8: 1-12.

Sánchez-Arcilla, A., Mösso, C., Sierra, J.P., Mestres, M., Harzallah, A., Senouci, M. and Raey, M.E., 2011. Climatic drivers of potential hazards in Mediterranean coasts. Regional Environmental Change, 11: 617-636.

Sánchez-Arcilla, A., Sierra, J.P., Brown, S., Casas-Prat, M., Nicholls, R.J., Lionello, P. and Conte, D., 2016a. A review of potential physical impacts on harbours in the 
Mediterranean Sea under climate change. Regional Environmental Change: 16: 24712484.

Sierra, J.P., Casanovas, I., Mösso, C., Mestres, M. and Sánchez-Arcilla, A., 2016. Vulnerability of Catalan (NW Mediterranean) ports to wave overtopping due to different scenarios of sea level rise. Regional Environmental Change, 16(5): 1457-1468.

Sierra, J.P. and Casas-Prat, M., 2014. Analysis of potential impacts on coastal areas due to changes in wave conditions. Climatic Change, 124: 861-876.

Sierra, J.P., Casas-Prat, M., Virgili, M., Mösso, C. and Sánchez-Arcilla, A., 2015. Impacts on wave-driven harbour agitation due to climate change in Catalan ports. Natural Hazards and Earth System Sciences, 15(8): 1695-1709.

Sierra, J.P., Genius, A., Lionello, P., Mestres, M., Mösso, C. and Marzo, L., 2017. Modelling the impact of climate change on harbour operability: The Barcelona port case study. Submitted to Ocen Engineering.

Suzuki, T., Zijlema, M., Burger, B., Meijer, M.C. and Narayan, S., 2012. Wave dissipation by vegetation with layer schematization in SWAN. Coastal Engineering, 59: 64-71.

Temmerman, S., Meire, P., Bouma, T.J., Herman, P.M., Ysebaert, T. and de Vriend, H.J., 2013. Ecosystem-based coastal defence in the face of global change. Nature, 504(7478): 7983.

Temmerman, S., Vries, M.B.D. and Bouma, T.J., 2012. Coastal marsh die-off and reduced attenuation of coastal floods: A model analysis. Global and Planetary Change, 92-93: 267-274.

van Loon-Steensma, J.M., 2015. Salt marshes to adapt the flood defences along the Dutch Wadden Sea coast. Mitigation and Adaptation Strategies for Global Change, 20(6): 929948.

Verduin, J.J. and Backhaus, J.O., 2000. Dynamics of plant-flow interactions for the seagrass Amphibolis antarctica: Field observations and model simulations. Estuarine, Coastal and Shelf Science, 50(2): 185-204.

Vuik, V., Jonkman, S.N., Borsje, B.W. and Suzuki, T., 2016. Nature-based flood protection: The efficiency of vegetated foreshores for reducing wave loads on coastal dikes. Coastal Engineering, 116: 42-56.

Zacharioudaki, A. and Reeve, D.E., 2011. Shoreline evolution under climate change wave scenarios. Climatic Change, 108(1): 73-105.

Figure captions (images as individual files separate to your MS Word text file).

Figure 1. Study area (Catalan coast, NW Mediterranean Sea) and location of the pilot cases: Cases d'Alcanar and Canyelles harbours.

Figure 2. Projected evolution of SLR during the $21^{\text {st }}$ century for the three scenarios considered in this paper (after AR5 of IPCC, 2013).

Figure 3. Lay-out of the proposed seagrass meadow in front of Cala Canyelles harbour, illustrating a "green" intervention to reduce overtopping under future climates.

Figure 4. Lay-out of the proposed seagrass meadows (small size left panel and large size right panel) at Cases d'Alcanar port entrance, illustrating a "green" intervention to reduce wave agitation within the port.

Figure 5. Wave attenuation at Cala Canyelles harbour, due to a Zostera Marina meadow. The boundary conditions are a southern wave storm of $5 \mathrm{~m}$ significant wave height $\left(\mathrm{H}_{\mathrm{s} 0}\right)$, plus a SLR of $0.47 \mathrm{~m}$. The proposed meadow is within the four green diamond points. The coloured areas denote the reduction of $\mathrm{H}_{\mathrm{s}}$ with respect to the baseline (no meadow). $\mathrm{H}_{\mathrm{swv}}$ and $\mathrm{H}_{\mathrm{sv}}$ denote the significant wave height without and with vegetation respectively. 
Figure 6. Ratio between significant wave heights at the Cala Canyelles breakwater toe with vegetation $\left(\mathrm{H}_{\mathrm{sv}}\right)$ and without vegetation $\left(\mathrm{H}_{\mathrm{swv}}\right)$ vs the offshore significant wave height $\left(\mathrm{H}_{\mathrm{s} 0}\right)$. Left: low-density meadow (50 stems $/ \mathrm{m}^{2}$ ). Right: high-density meadow $\left(100 \mathrm{stems} / \mathrm{m}^{2}\right.$ ).

Figure 7. Ratio between overtopping discharges for the Cala Canyelles breakwater with vegetation $\left(q_{v}\right)$ and without vegetation $\left(q_{w v}\right)$ vs the offshore significant wave height $\left(H_{s 0}\right)$. Left: low-density meadow (50 stems $/ \mathrm{m}^{2}$ ). Right: high-density meadow $\left(100 \mathrm{stems} / \mathrm{m}^{2}\right)$.

Figure 8. Reduction of overtopping discharges over the Cala Canyelles port breakwater if vegetation is placed in front of it, calculated for the 6 wave directions reaching the port. Left: present conditions. Right: with SLR $=0.47 \mathrm{~m}$. The return period of the significant wave height selected for the assessment is 5 years for all the sectors. Results cover the low-density and high-density seagrass meadows.

Figure 9. Upper panel: Wave pattern inside Cases d'Alcanar port for E waves with an offshore significant wave height $\mathrm{H}_{\mathrm{s} 0}=2.5 \mathrm{~m}$ for the present port configuration. Middle panel: Percentage of $H_{s}$ reduction with respect to the previous plot with the meadow of layout $A$ at the bottom entrance. Bottom panel: Percentage of $\mathrm{H}_{\mathrm{s}}$ reduction with respect to the upper plot with the meadow of layout $B$ at the harbour entrance.

\section{Table Captions}

Table 1. Average reduction (in \%) of significant wave height at the breakwater toe with vegetation (with two different densities) with respect to conditions without vegetation. These values have been computed for 4 scenarios of SLR. Values within brackets indicate the reduction interval.

Table 2. Average variation (in \%) of overtopping discharge (q) with respect to present conditions (without vegetation and SLR $=0 \mathrm{~m}$ ) for two different vegetation densities and the different scenarios of SLR considered. Negative values indicate q reduction while positive values imply larger q.

Table 3. Projected change (future minus present in \%) of the spatial averaged Hs at the Cases d'Alcanar port. HIR_E, RAC_E, RCA_E, REM_E and RCA_H are the acronyms of the wind data sets (see Casas-Prat and Sierra, 2013). 


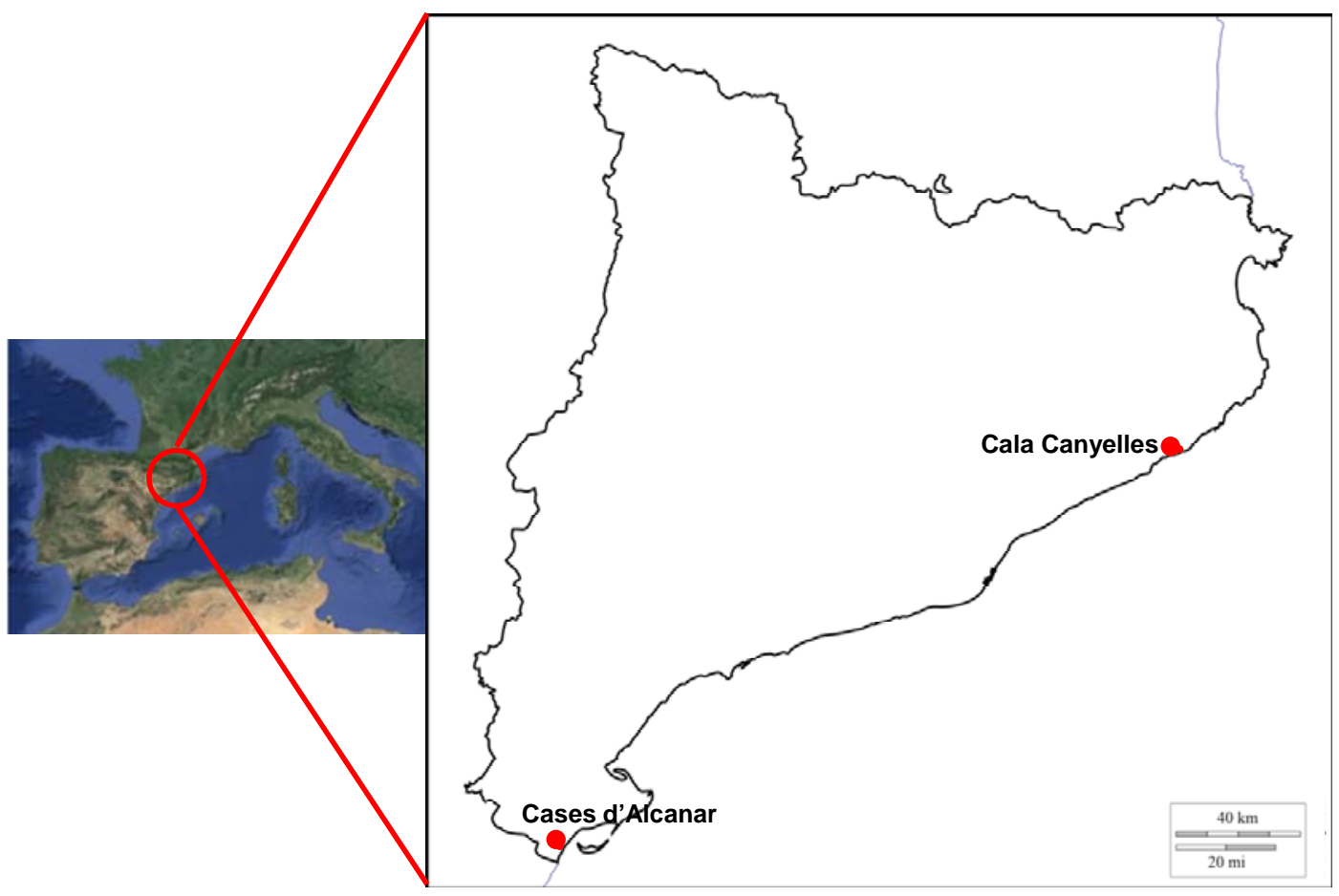

Figure 1. Study area (Catalan coast, NW Mediterranean Sea) and location of the pilot cases: Cases d'Alcanar and Canyelles harbours. 


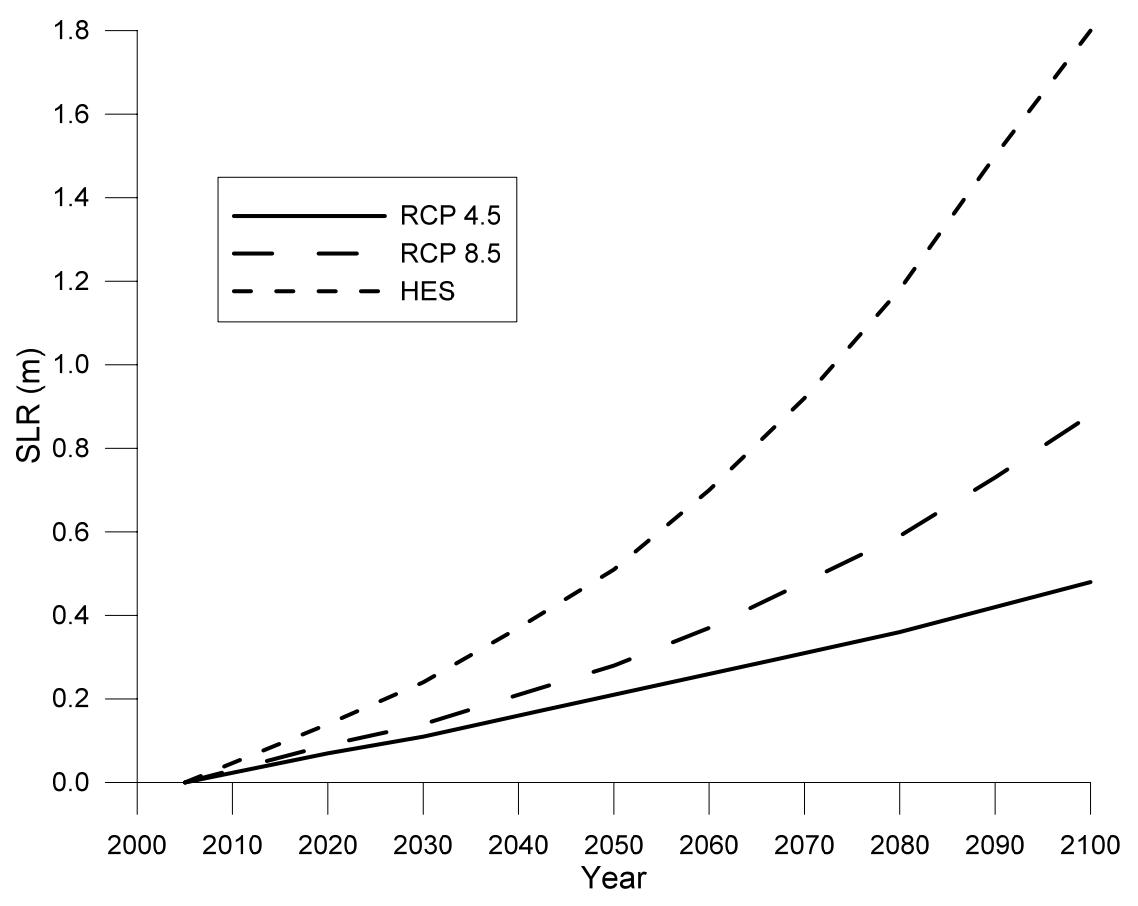

Figure 2. Projected evolution of SLR during the $21^{\text {st }}$ century for the three scenarios considered in this paper (after AR5 of IPCC, 2013). 


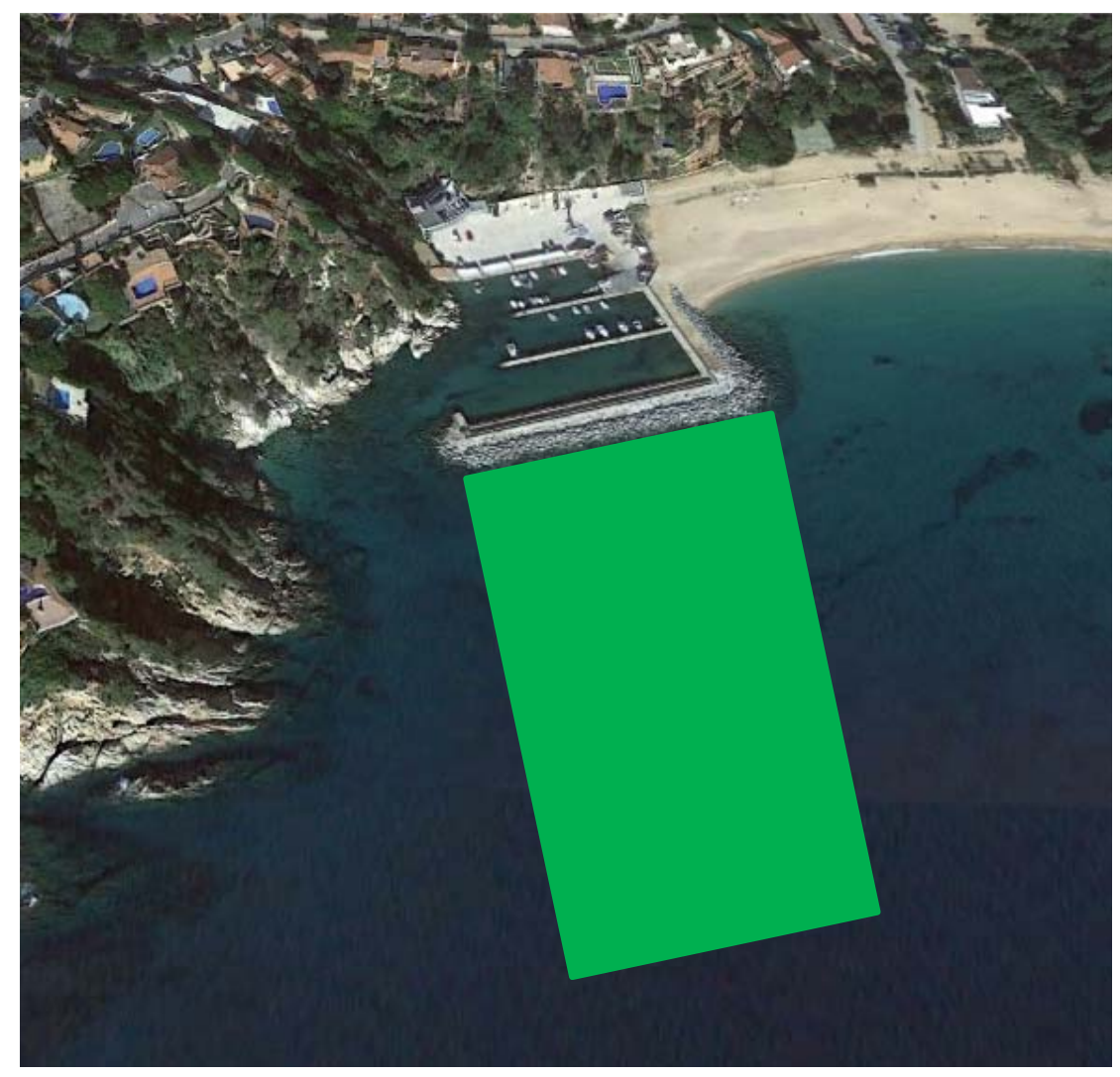

Figure 3. Lay-out of the proposed seagrass meadow in front of Cala Canyelles harbour, illustrating a "green" intervention to reduce overtopping under future climates. 


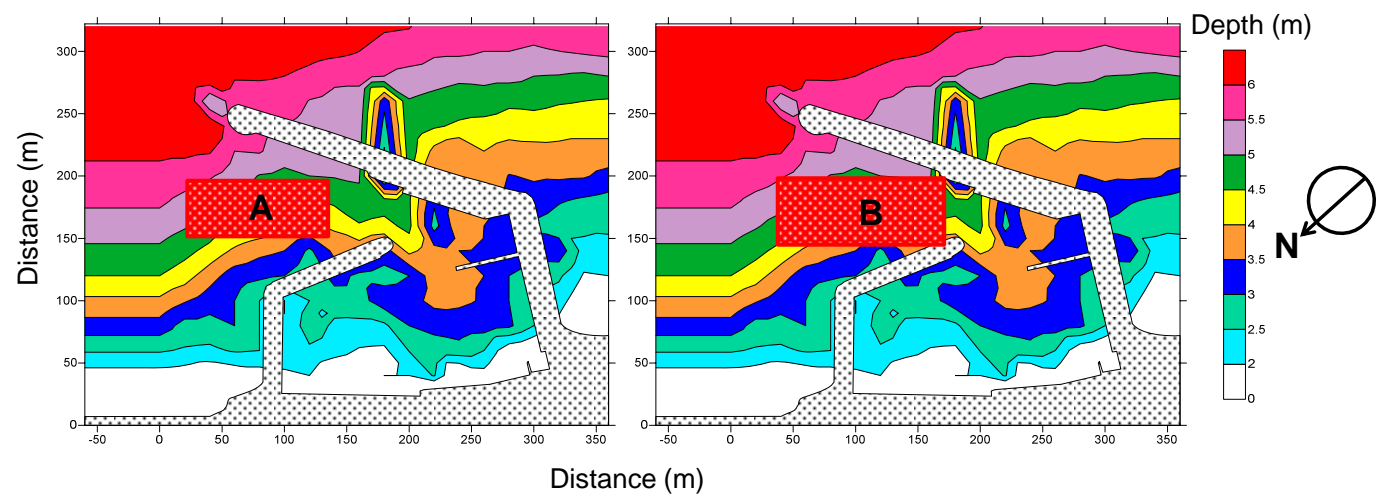

Figure 4. Lay-out of the proposed seagrass meadows (small size left panel and large size right panel) at Cases d'Alcanar port entrance, illustrating a "green" intervention to reduce wave agitation within the port. 


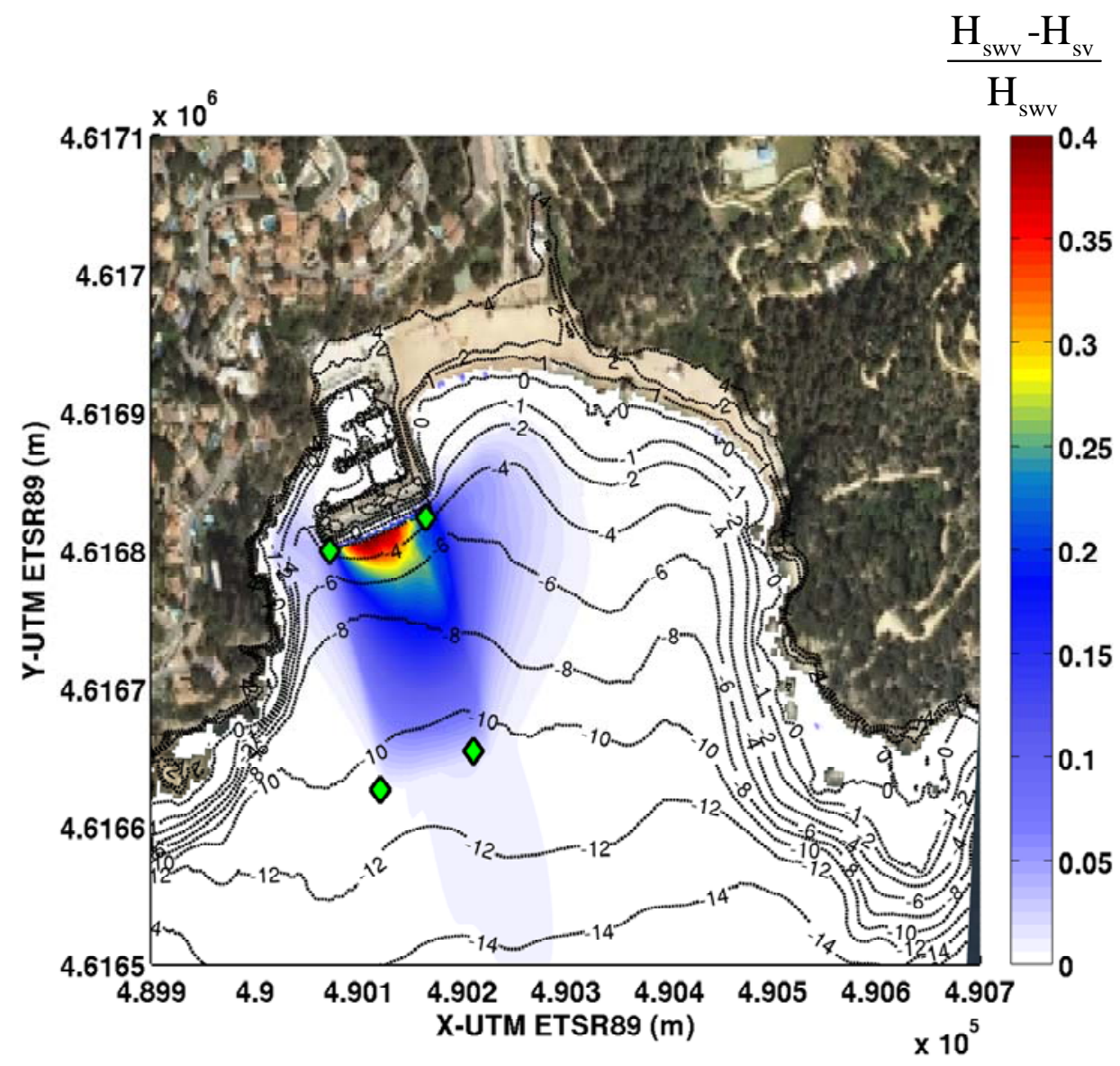

Figure 5. Wave attenuation at Cala Canyelles harbour, due to a Zostera Marina meadow. The boundary conditions are a southern wave storm of $5 \mathrm{~m}$ significant wave height $\left(\mathrm{H}_{\mathrm{s} 0}\right)$, plus a SLR of $0.47 \mathrm{~m}$. The proposed meadow is within the four green diamond points. The coloured areas denote the reduction of $\mathrm{H}_{\mathrm{s}}$ with respect to the baseline (no meadow). $\mathrm{H}_{\mathrm{sw}}$ and $\mathrm{H}_{\mathrm{sv}}$ denote the significant wave height without and with vegetation respectively. 

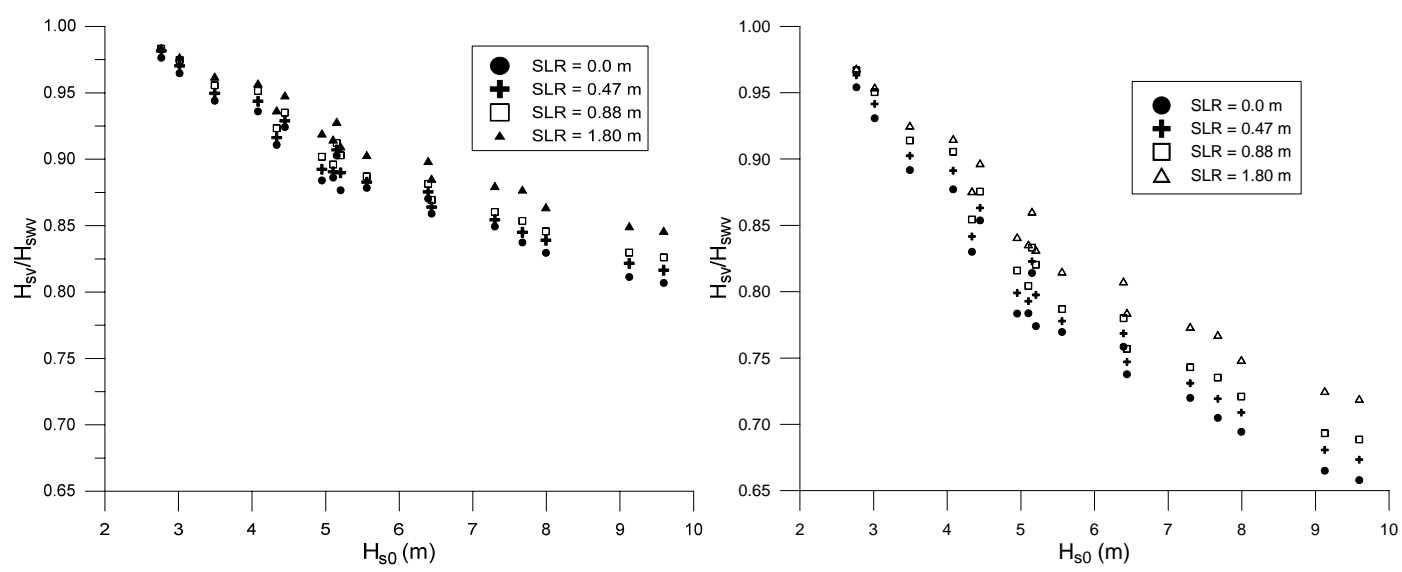

Figure 6. Ratio between significant wave heights at the Cala Canyelles breakwater toe with vegetation $\left(\mathrm{H}_{\mathrm{sv}}\right)$ and without vegetation $\left(\mathrm{H}_{\mathrm{swv}}\right)$ vs the offshore significant wave height $\left(\mathrm{H}_{\mathrm{s} 0}\right)$. Left: low-density meadow $\left(50 \mathrm{stems} / \mathrm{m}^{2}\right)$. Right: high-density meadow $\left(100 \mathrm{stems} / \mathrm{m}^{2}\right)$. 

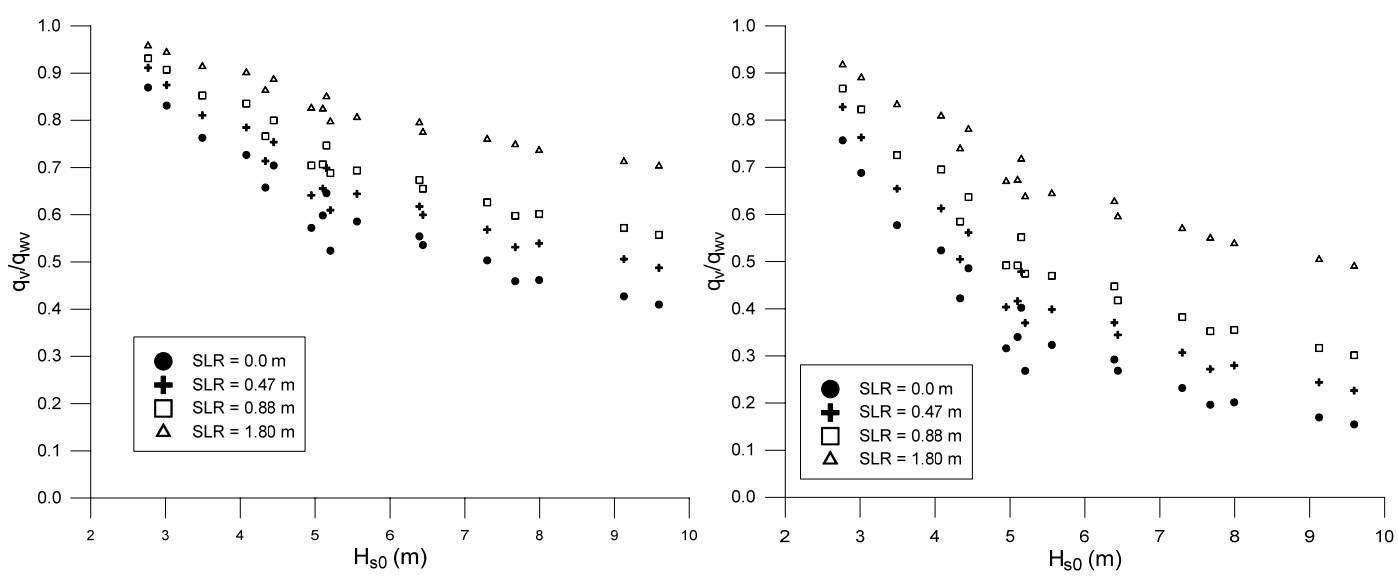

Figure 7. Ratio between overtopping discharges for the Cala Canyelles breakwater with vegetation ( $\left.q_{v}\right)$ and without vegetation $\left(q_{w}\right)$ vs the offshore significant wave height $\left(\mathrm{H}_{\mathrm{s} 0}\right)$. Left: low-density meadow (50 stems $/ \mathrm{m}^{2}$ ). Right: high-density meadow (100 stems $/ \mathrm{m}^{2}$ ). 

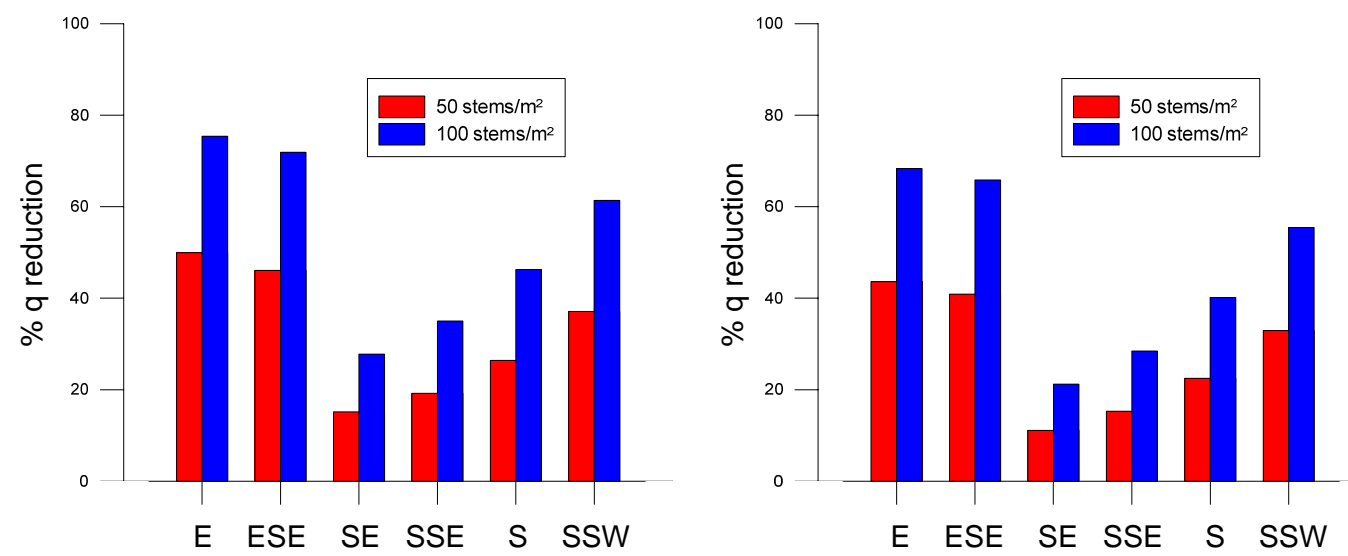

Figure 8. Reduction of overtopping discharges over the Cala Canyelles port breakwater if vegetation is placed in front of it, calculated for the 6 wave directions reaching the port. Left: present conditions. Right: with SLR $=0.47 \mathrm{~m}$. The return period of the significant wave height selected for the assessment is 5 years for all the sectors. Results cover the low-density and high-density seagrass meadows. 

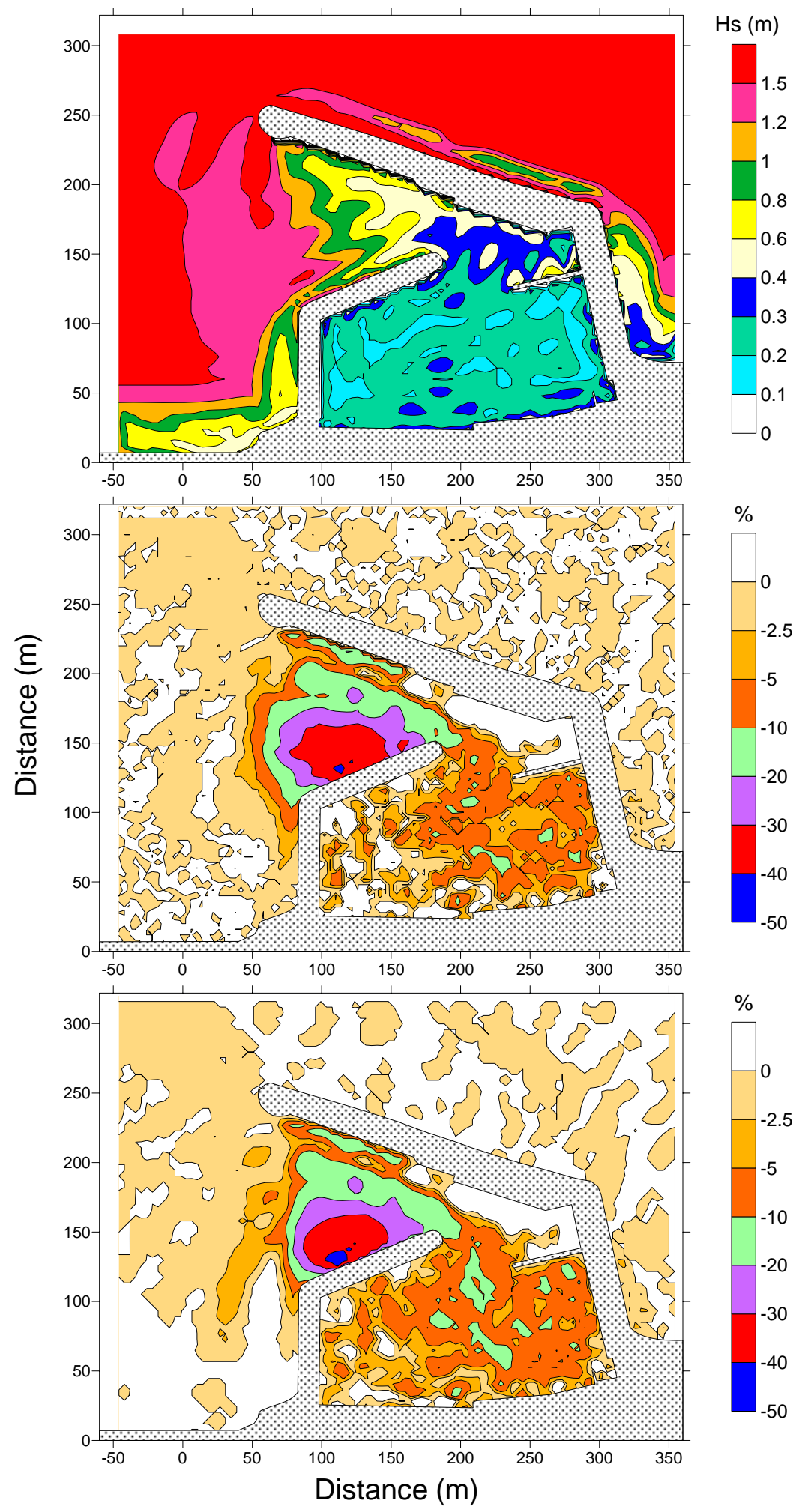

Figure 9. Upper panel: Wave pattern inside Cases d'Alcanar port for $E$ waves with an offshore significant wave height $\mathrm{H}_{\mathrm{s} 0}=2.5 \mathrm{~m}$ for the present port configuration. Middle panel: Percentage of $\mathrm{H}_{\mathrm{s}}$ reduction with respect to the previous plot with the meadow of layout $A$ at the bottom entrance. Bottom panel: Percentage of $\mathrm{H}_{s}$ reduction with respect to the upper plot with the meadow of layout $B$ at the harbour entrance. 


\begin{tabular}{|c|c|c|c|c|}
\hline Density & SLR $=\mathbf{0} \mathbf{~ m}$ & SLR $=\mathbf{0 . 4 7} \mathbf{~ m}$ & SLR $=\mathbf{0 . 8 8} \mathbf{~ m}$ & SLR $=1.80 ~ \mathbf{~}$ \\
\hline $50 \mathrm{stems} / \mathrm{m}^{2}$ & $11.4(2.4-19.3)$ & $10.7(1.8-18.4)$ & $10.1(1.7-17.4)$ & $8.7(1.6-15.4)$ \\
\hline $100 \mathrm{stems} / \mathrm{m}^{2}$ & $21.1(4.6-34.2)$ & $19.9(3.7-32.7)$ & $18.6(3.3-31.1)$ & $16.4(3.2-28.1)$ \\
\hline
\end{tabular}

Table 1. Average reduction (in \%) of significant wave height at the breakwater toe with vegetation (with two different densities) with respect to conditions without vegetation. These values have been computed for 4 scenarios of SLR. Values within brackets indicate the reduction interval.

\begin{tabular}{|c|c|c|c|}
\hline SLR & Without vegetation & $\mathbf{5 0} \mathbf{~ s t e m s} / \mathbf{m}^{2}$ & $\mathbf{1 0 0} \mathbf{~ s t e m s} / \mathbf{m}^{2}$ \\
\hline $0.0 \mathrm{~m}$ & 0.0 & -39.8 & -63.2 \\
\hline $0.47 \mathrm{~m}$ & 90.1 & 27.1 & -13.8 \\
\hline $0.88 \mathrm{~m}$ & 225.9 & 137.6 & 75.9 \\
\hline $1.80 \mathrm{~m}$ & 929.3 & 767.1 & 633.2 \\
\hline
\end{tabular}

Table 2. Average variation (in \%) of overtopping discharge $(q)$ with respect to present conditions (without vegetation and SLR = $0 \mathrm{~m}$ ) for two different vegetation densities and the different scenarios of SLR considered. Negative values indicate $q$ reduction while positive values imply larger $q$.

\begin{tabular}{|l|c|c|c|c|c|c|}
\hline \multirow{2}{*}{ Situation } & \multicolumn{4}{|c|}{ Model } & Ensemble \\
\cline { 2 - 6 } & HIR_E & RAC_E & RCA_E & REM_E & RCA_H & Average \\
\hline Future without seagrass & $2.68 \%$ & $4.27 \%$ & $5.59 \%$ & $-0.27 \%$ & $4.64 \%$ & $3.38 \%$ \\
\hline Future Seagrass layout A & $-7.69 \%$ & $-5.93 \%$ & $-5.33 \%$ & $-10.95 \%$ & $-4.63 \%$ & $-6.91 \%$ \\
\hline Future Seagrass layout B & $-7.75 \%$ & $-7.38 \%$ & $-6.73 \%$ & $-11.05 \%$ & $-5.37 \%$ & $-7.66 \%$ \\
\hline
\end{tabular}

Table 3. Projected change (future minus present in \%) of the spatial averaged $H_{s}$ at the Cases d'Alcanar port. HIR_E, RAC_E, RCA_E, REM_E and RCA_H are the acronyms of the wind data sets (see Casas-Prat and Sierra, 2013). 